\title{
POLUIÇÃO ATMOSFÉRICA ADVINDA DE QUEIMADAS DE CANA-DE-AÇÚCAR PARA A REGIÃO METROPOLITANA DE SÃO PAULO
}

Thiago Souza Silveira ${ }^{1}$

\section{RESUMO}

O presente trabalho teve como objetivo a análise do transporte de poluentes atmosféricos gerados na queima da cana-de-açúcar no estado de São Paulo durante o ano de 2010, pois a cultura canavieira no estado é muito forte, abastecendo o mercado alimentício, energético e de bebidas. Porém, apresenta um grave problema com a queima da plantação antes da colheita, gerando poluição e enfraquecendo o argumento de "energia limpa". Baseado nas teorias os Sistemas e dos Geossistemas, na dinâmica atmosférica e no uso de modelagem como instrumento de análise; além do levantamento dos dados atmosféricos e de poluição aferidos e mapeamento da área e das queimadas, concluiu-se que há áreas com picos de poluição ao longo do ano; a pluma de poluentes vai para Região Metropolitana de São Paulo em certas condições atmosféricas e ocorreram eventos generalizados de queima de biomassa, principalmente entre agosto e setembro, confirmando a hipótese observando a distribuição e concentração de poluentes segundo os dados de circulação atmosférica e de poluição.

PALAVRAS-CHAVE: Poluição Atmosférica. Transporte de Poluentes. Queimadas.

\section{AIR POLLUTION FROM SUGARCANE BURNING TO METROPOLITAN REGION OF SAO PAULO}

\begin{abstract}
This study has the objective to analyze the air pollution transport from sugarcane burn in Sao Paulo State in 2010, as the planted areas are very vast, it supplies the food, energy and beverage industry. By the other hand, it presents severe problem of burning culture before the harvest period, it causes air pollution and disqualify the "clean energy" argument. Based on the System and Geosystem theories, on atmospheric dynamic and using models as analysis instrument; in addiction getting atmospheric and pollution data observed, mapping sugarcane and the burned area, it was concluded there were parts with peaks of pollution during this year, the plume of
\end{abstract}

${ }^{1}$ Mestrando em geografia física, Universidade de São Paulo. thiagosousilveira@yahoo.com.br. 


\title{
INCENDIOS DE CONTAMINACIÓN DEL AIRE DE DERIVADOS DE CAÑA DE AZÚCAR PARA LA REGIÓN METROPOLITANA DE SÃO PAULO
}

\begin{abstract}
RESUMEN
Este estudio tuvo como objetivo analizar el transporte de los contaminantes atmosféricos generados en la quema de la caña de azúcar en el estado de São Paulo en 2010, ya que el cultivo de caña de azúcar en el estado es muy fuerte, lo que alimentó el mercado de alimentos, energía y bebidas. Sin embargo, tiene un problema serio con la siembra de la quema antes de la cosecha, lo que genera contaminación y debilitando el argumento de "energía limpia". Sobre la base de las teorías de sistemas y Geosystems en la dinámica atmosférica y el uso de modelos como herramienta de análisis; y un estudio de los datos medidos y la contaminación atmosférica y la cartografía de la zona y se quema, se concluye que hay áreas de los picos de contaminación a lo largo del año; la pluma contaminante va a la Región Metropolitana de São Paulo, en ciertas condiciones atmosféricas y fueron eventos generalizadas de la quema de biomasa, sobre todo entre agosto y septiembre, lo que confirma la hipótesis mediante la observación de la distribución y concentración de contaminantes en virtud de los datos de circulación atmosférica y la contaminación.
\end{abstract}

PALABRAS CLAVE: contaminación del aire. Transporte de contaminantes. Quemado.

\section{INTRODUÇÃO}

O Brasil é o país com a maior produção de cana-de-açúcar do mundo e o estado de São Paulo detém 40\% da produção nacional (CONFEDERAÇÃO DA AGRICULTURA E PECUÁRIA DO BRASIL, 2012). Por outro lado, as formas de manejo da terra quando se trata desse cultivo são bastante rudimentares e ainda é usada a queimada do canavial como um de seus processos de colheita. 
Com o advento do motor movido a etanol, e, posteriormente, o desenvolvimento dos motores bicombustíveis, a área de plantio de cana-de-açúcar aumentou bastante para suprir a demanda energética (SECRETARIA DE AGRICULTURA E ABASTECIMENTO, 2008).

Esse aumento causou alguns impactos tanto ambientais como sociais, tais como o agravamento da má distribuição de renda no campo, jornadas de trabalho estafantes e poluição do ar transportada para outros locais (BARROCAS, 2001).

A maior expansão da área de cultivo foi em 2009, portanto, o ano de 2010 pode servir de base para a investigação, e sendo São Paulo o maior produtor, será também o recorte geográfico da pesquisa.

\section{OBJETIVO}

Verificar a sazonalidade de poluentes atmosféricos, $\mathrm{CO}$ e $\mathrm{MP}_{10}$, originados pela queima de canaviais no estado de São Paulo, em 2010, em situações sinóticas distintas.

\section{EVOLUÇÃO DA ÁREA DE ESTUDO}

São Paulo teve um aumento muito grande da área de plantio de cana, e os seus processos de colheita nem sempre obedeceram a evolução de manejo, apresentando ainda muitas fazendas que queimam a cultura antes. Segundo o Programa CANASAT (2011) do Instituto de Pesquisas Espaciais (INPE), entre 2009 e 2010 houve uma grande expansão da cana no estado como observado na Figura 1. 
Figura 1: Evolução das áreas de cana no estado de São Paulo

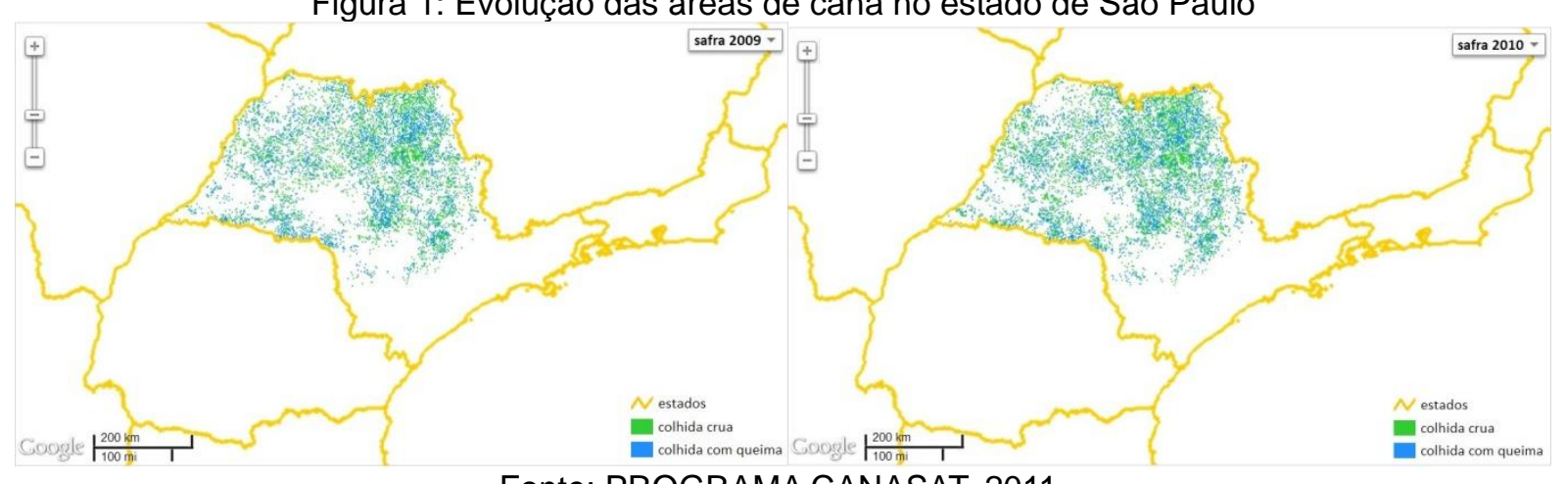

Fonte: PROGRAMA CANASAT, 2011.

\section{CUSTOS SOCIAIS DA CANA}

Como a questão social rural no país não foi resolvida, alguns contrastes puderam ser verificados e eles influenciaram na possibilidade de financiamento do processo de mecanização da lavoura ou a continuidade dos boias-frias na plantação.

A máquina rende o trabalho de quase 5 homens, mas custa caro e é de difícil financiamento. Como nem todos os trabalhadores são registrados, em geral cada um pode custar $R \$ 622,00$ (ZANCUL, 2010), que ao longo de 25 anos de trabalho custa $\mathrm{R} \$ 373.300,00$ para o proprietário da terra. Uma vez que ele financie a colheitadeira, com o tempo ele consegue saldar a dívida, mas se ele queimar a cana e usar a máquina ao mesmo tempo a produção aumenta significativamente.

\begin{tabular}{|c|c|c|}
\hline \multicolumn{3}{|c|}{$\begin{array}{r}\text { Quadro 1: Custo de produção, inves } \\
\text { Custo } x \text { Produção }\end{array}$} \\
\hline 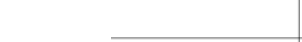 & Homem & Máquina \\
\hline Queimando & $9 \mathrm{~T} / \mathrm{dia}$ & $32,29 \mathrm{~T} / \mathrm{dia}$ \\
\hline Sem Queimar & 3,8 T/dia & 25 T/dia \\
\hline \multicolumn{3}{|c|}{ Custo de Investimento X Tempo } \\
\hline Homem (cada) & $\mathrm{R} \$ 622,00$ ao mês & 25 anos aprox. \\
\hline Máquina & $\mathrm{R} \$ 1.000 .000$ & 10 anos \\
\hline
\end{tabular}

\section{METODOLOGIA}

O estudo foi realizado com bases na modelagem atmosférica, no levantamento e análise da qualidade do ar da CETESB (Companhia de Tecnologia de 
Volume 10, Número 4, 2014

Dilemas da

Sustentabilidade Urbana

Saneamento Ambiental de São Paulo) e do modelo CCATT-BRAMS (Coupled Aerosol and Tracer Transport model to the Brazilian developments on the Regional Atmospheric Modelling System) do INPE e nos dados de reanálise do ETA.

\section{RESULTADOS}

A análise dos dados da CETESB apresentou os seguintes dados para Material Particulado ( $\mathrm{MP}_{10}$ ) e Monóxido de Carbono (CO), poluentes mais comuns em queima de biomassa.

Quadro 2: Comparativo entre os poluentes em SP em 2010

\begin{tabular}{|c|c|c|}
\hline \multicolumn{3}{|c|}{ Dados CETESB 2010 } \\
\hline MP $_{10}$ & Gases & CO \\
\hline 296.735 & Amostras & 102.594 \\
\hline 40 & Estações & 15 \\
\hline Jun-Ago - Set & Piores Meses & Jun - Jul - Ago \\
\hline Madrugada & Horas de Pico & Noite \\
\hline
\end{tabular}

Fonte: CETESB 2011

Analisando a distribuição dos poluentes, tanto para $\mathrm{CO}$ quanto para $\mathrm{MP}_{10}$, foi verificada uma sazonalidade com seu pico nos meses mais secos, em setembro. Foi realizada também uma comparação entre cidades de diversos perfis econômicos, a qual apresentou, dentre as cidades produtoras de cana, um pico em setembro, que também é o auge da colheita da cana. Para cidades urbanas esse pico foi em agosto, enquanto nas agropecuárias, ou cidades menores aconteceu entre julho e agosto. 
Figura 2: Espacialização de $\mathrm{MP}_{10}$ no estado de São Paulo em 2010

Prancha de Distribuição Espacial de Material Particulado: máxima absoluta mensal
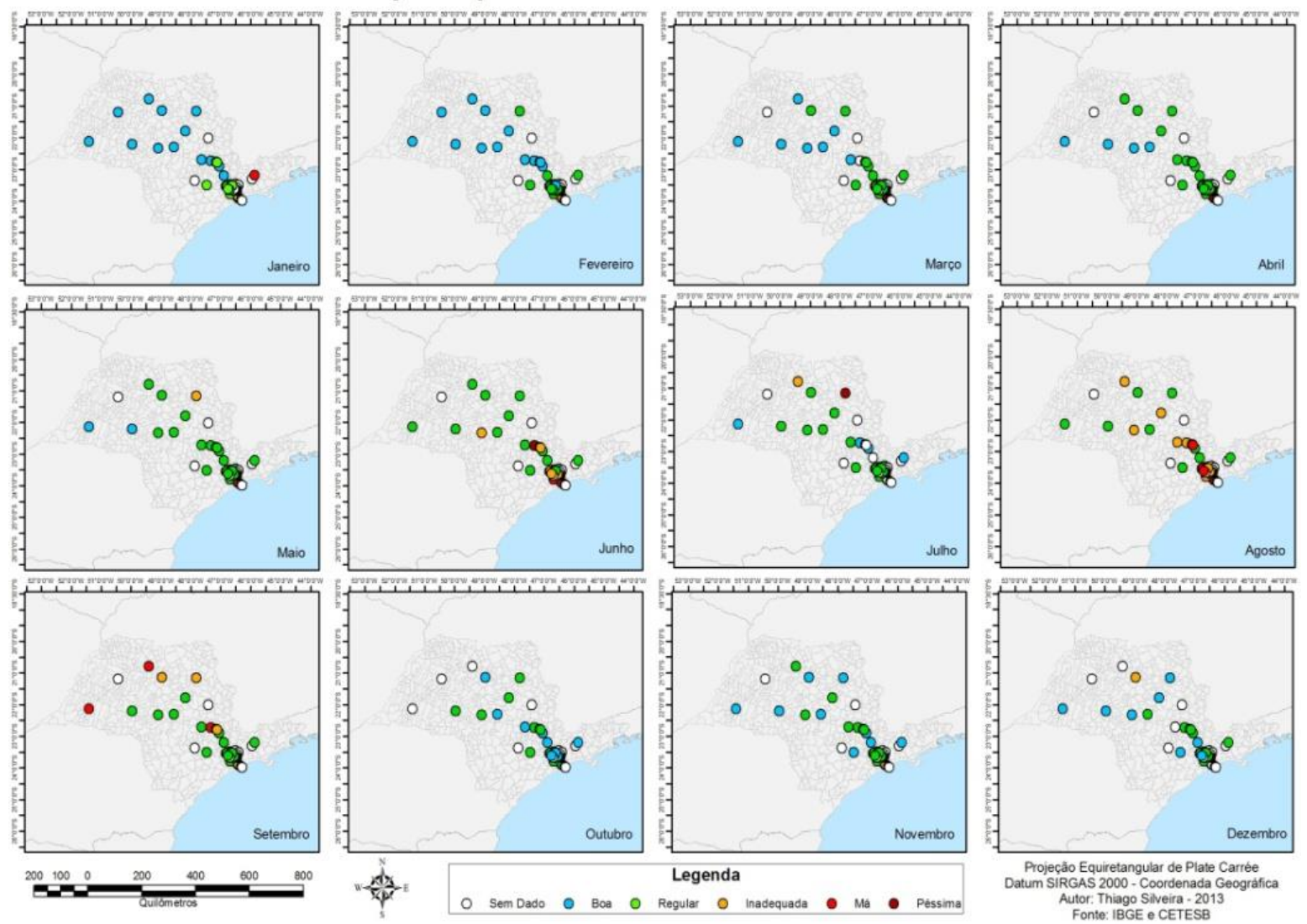

A análise atmosférica da reanálise ETA dos períodos escolhidos com a maior marca de poluentes, como o dia 16 de junho, quando houve a maior de $\mathrm{CO}$ e 24 de setembro de $\mathrm{MP}_{10}$. Ambas as análises atmosféricas mostraram algumas particularidades, em junho havia ventos fracos, no sentido NW-SE em níveis baixos da atmosfera, havia uma situação pré-frontal no estado e queimada no dia.

Em setembro havia ventos fracos, de diversas direções durante o dia, que não deixaram o $\mathrm{MP}_{10}$ assentar, provocando, como na situação anterior, o acúmulo no ambiente. 
Figura 3: Situação atmosférica no período de maior marca de $\mathrm{CO}$ e de $\mathrm{MP}_{10}$
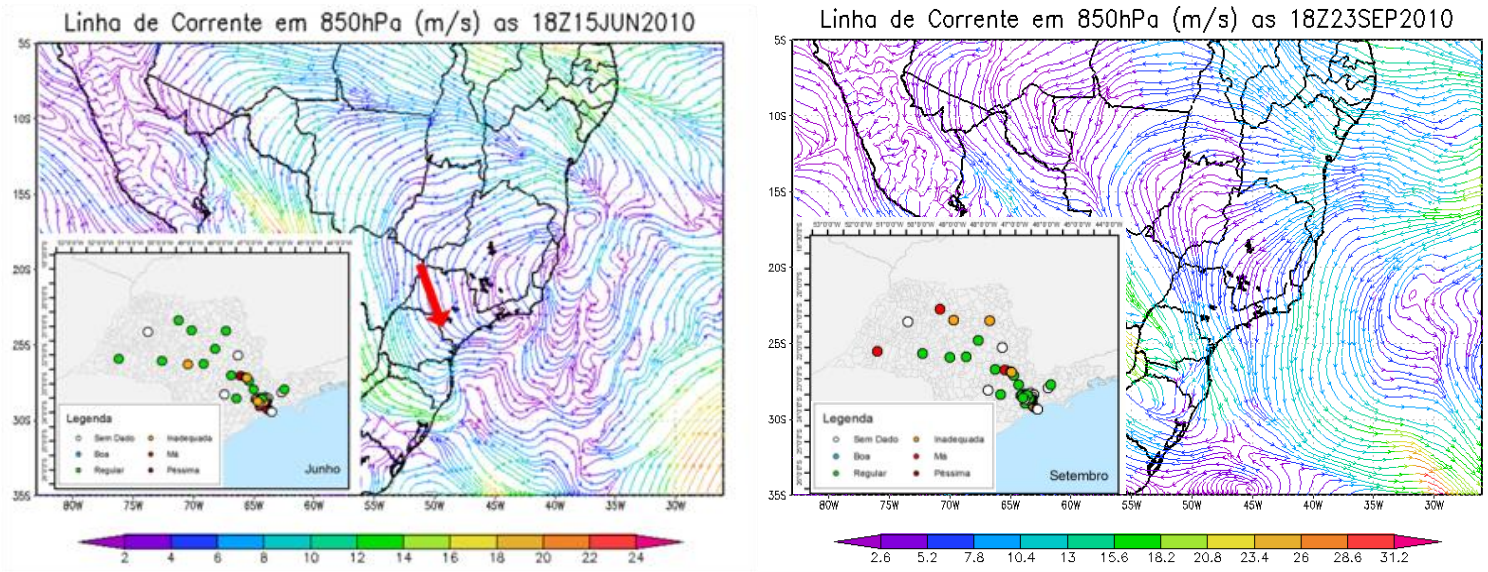

Através da análise com o CCATT-BRAMS, realizada numa parceria entre 0 INPE e a USP, onde a primeira instituição rodou o modelo e na universidade foi feita a interpretação dos dados, a pluma de poluição se direcionou para o local correto, mas houve falhas com relação à temperatura da superfície na ocasião. Isso gerou um problema, pois apesar da circulação normal de ventos estar carregando a pluma para o sul de Minas Gerais e leste do Mato Grosso do Sul, a temperatura elevada (mais de $40^{\circ} \mathrm{C}$ em junho) pode influenciar a pressão e a concentração que esses poluentes podem alcançar.

Com esses contratempos e a contradição comparada à reanálise ETA, não se pode validar a saída do modelo CCATT-BRAMS, apesar das teorias, das condições atmosféricas e de poluição parecerem, segundo os dados da CETESB e do INMET (Instituto Nacional de Meteorologia) dentro dos parâmetros. 
Figura 4: Verificação de problemas com o modelo CCATT-BRAMS

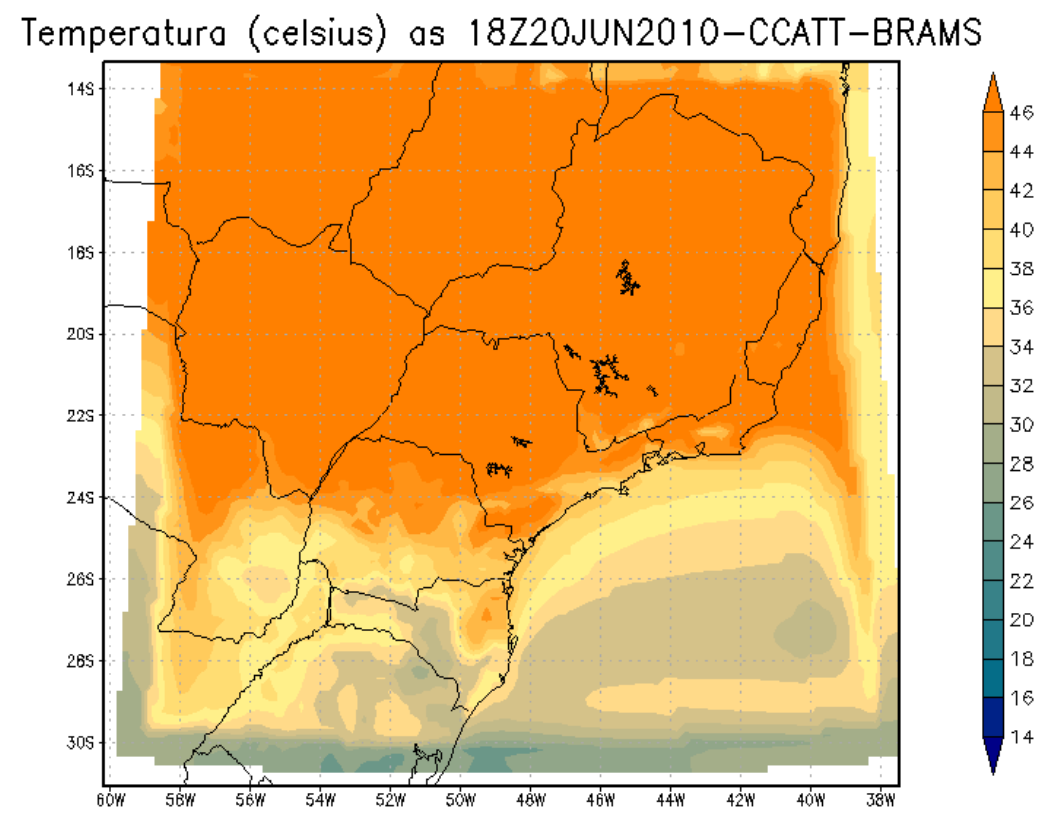

A simulação envolveu duas situações distintas, uma com a ocorrência de queimadas para a época (que já é monitorada via satélite e incorporada normalmente nas análises) e outra sem queimada. Essa simulação foi feita apenas em locais onde havia queima e plantação de cana. Depois uma junção desses para se saber qual é o impacto dessas queimadas, simulando a atmosfera com queima e suas emissões de poluentes e aquela onde não havia queima, apenas a poluição normal de fábricas e veículos, gerando o seguinte resultado: 
Figura 5: Diferença entre a concentração de $\mathrm{MP}_{2,5}(\mu \mathrm{g} \mathrm{m}-3)$ obtidas os experimentos com e sem queimada (EXP1-CTRL) para os horários de (a) 00, (b) 06, (c) 12 e (d) 18 horas do dia 24/set/2010 e linha de corrente a 10 metros para o mesmo período
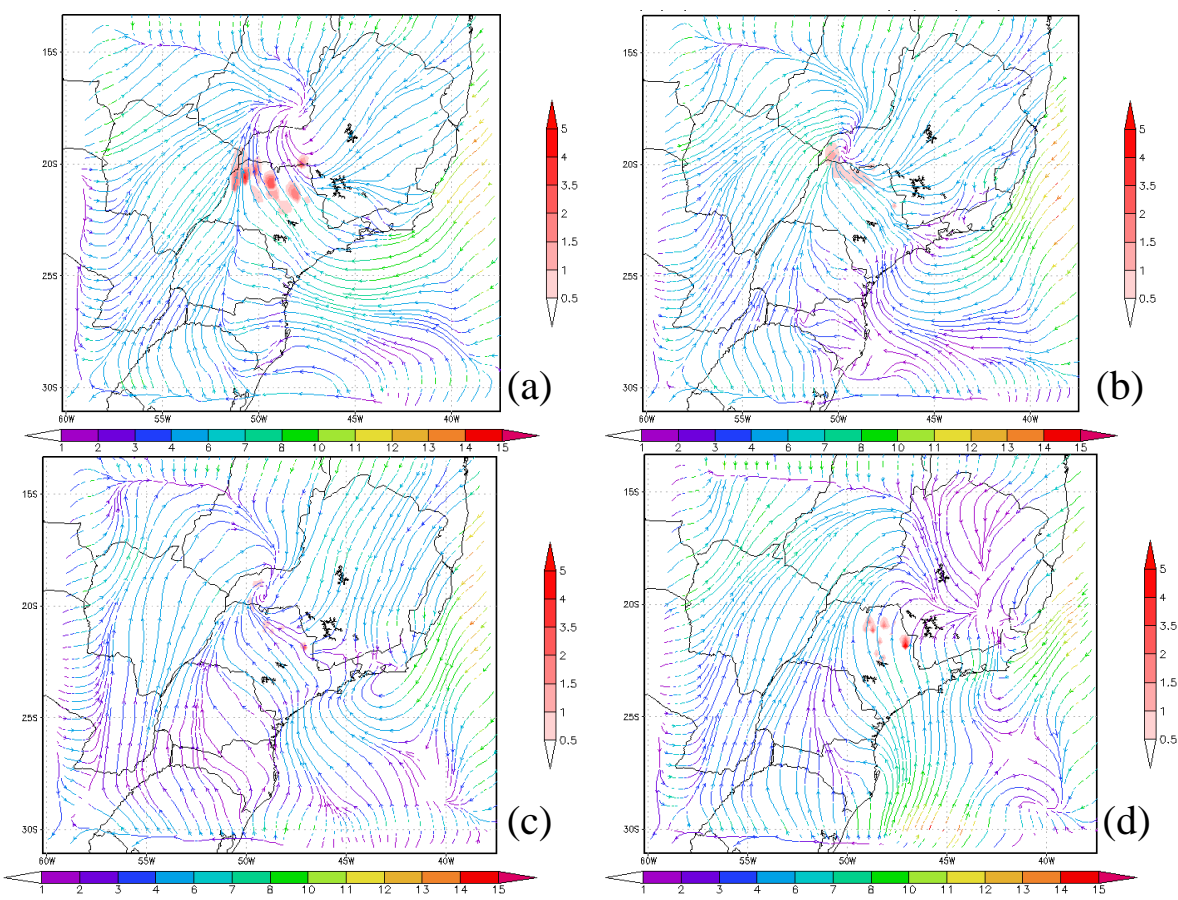

Os resultados, apesar de não poderem ser validados numericamente, se parecem com a simulação feita pelo ETA. Apresentando os mesmos ventos fracos, mas direção oposta quanto ao sentido. O que mudaria também a direção da pluma de poluentes.

Visto essa duplicidade de informação e considerando que é uma simulação da realidade, os dados dessa rodada devem ser desconsiderados quanto ao resultado de saída, sua contribuição na parte teórica e operacional é de grande ajuda e permite um avanço grande na ciência atmosférica, desde que ancorado na comparação com a realidade.

As análises das queimadas de biomassa em 2010 apontam uma sazonalidade dos incêndios e seu pico é em setembro, também auge da colheita de cana. Cruzando os dados onde havia plantação de cana e onde houve queima, observou-se que os canaviais contribuíram com $30 \%$ do total pirogênico. E analisando 
dia-a-dia, houve um ciclo de aumento de episódios à medida que se aproximava uma frente fria.

Figura 6: Análise do total de queimada de biomassa no estado de São Paulo em 2010

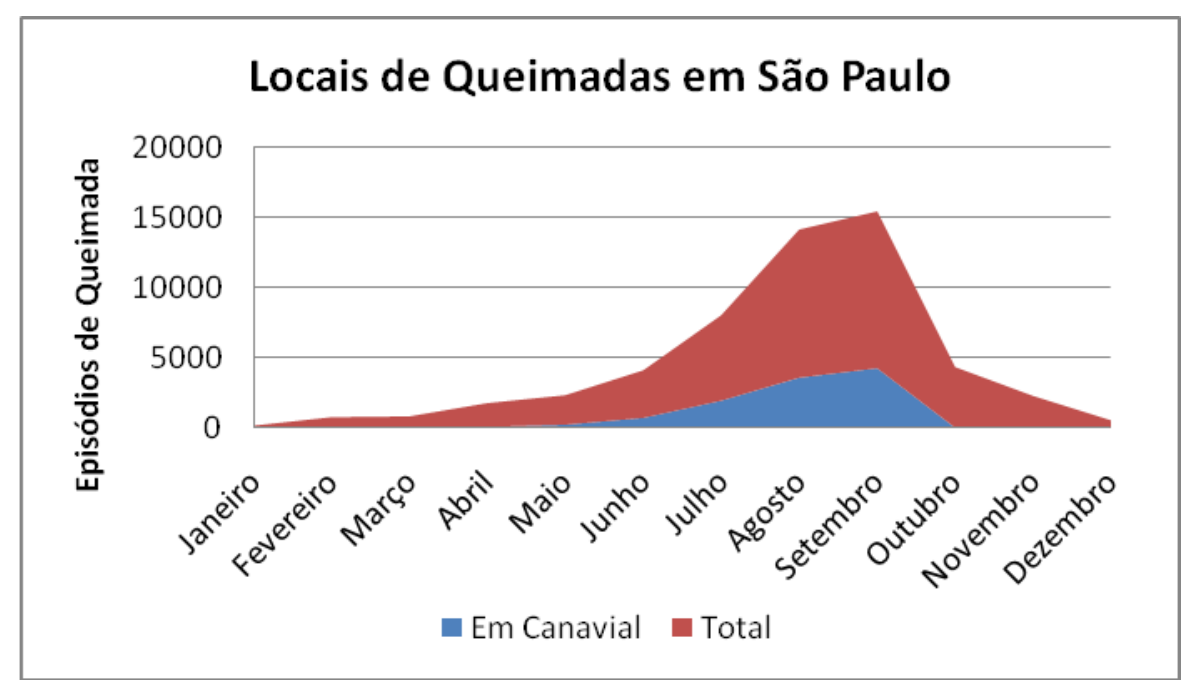

Fonte: INPE

Figura 7: Análise diária de queimada em canavial com picos cíclicos quando há chegada de frente fria

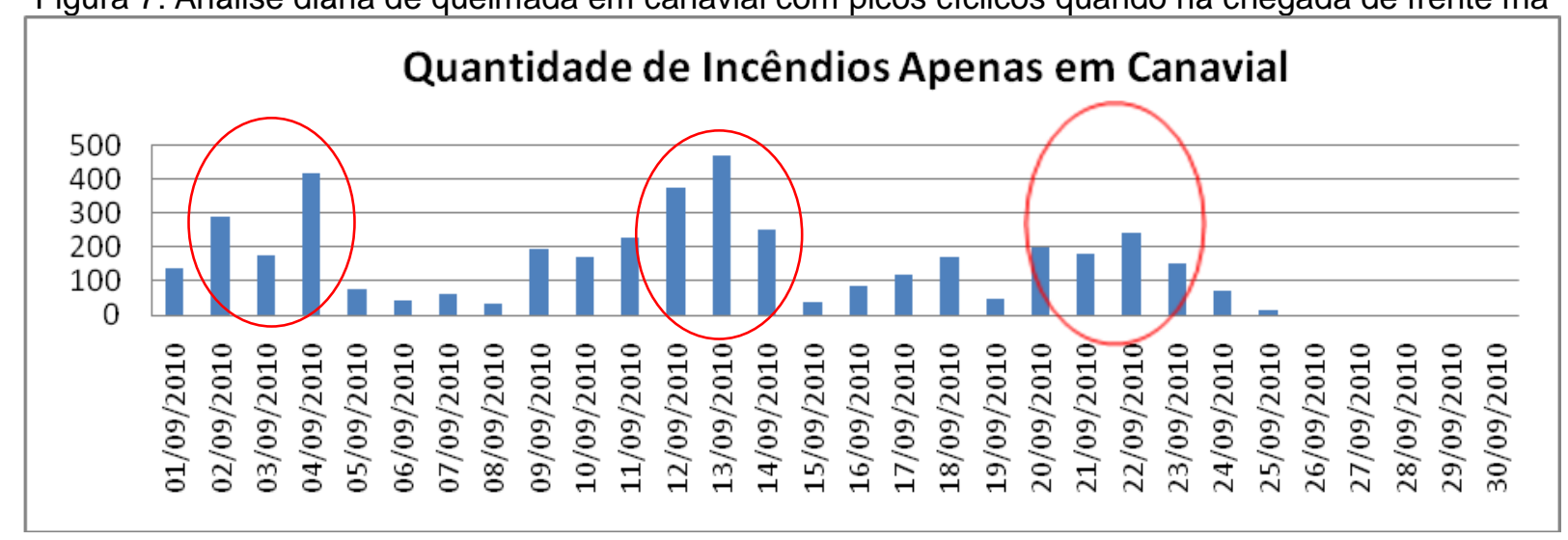

Fonte: INPE

As análises foram feitas de acordo com o banco de dados do INPE, sobre o monitoramento nacional de queimadas no Brasil, eles também oferecem a localização geográfica das ocorrências, onde se pôde espacializar e temporizar como mostrado na 
Figura 8:

Figura 8: Mapa das ocorrências de incêndios em canaviais em 2010
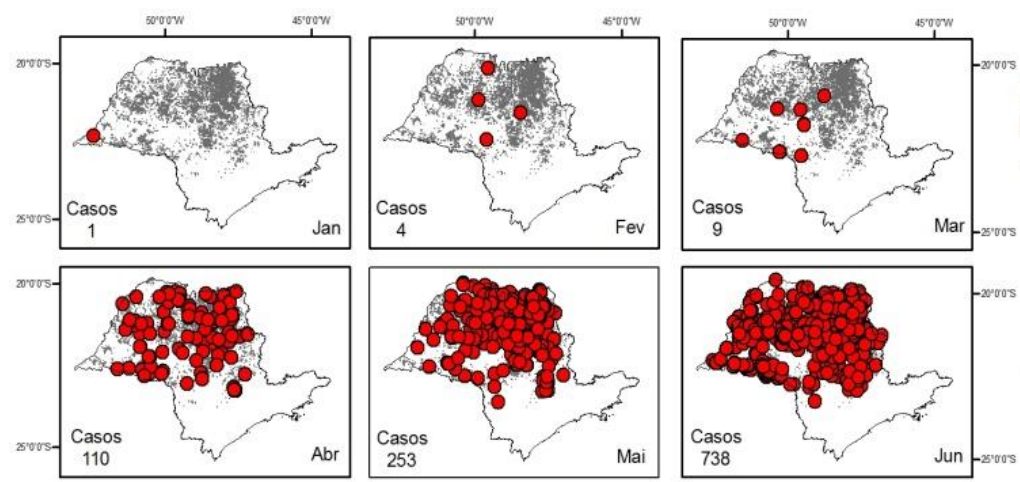

Focos de Incêndio

Mensal Apenas em

Áreas de Canavial
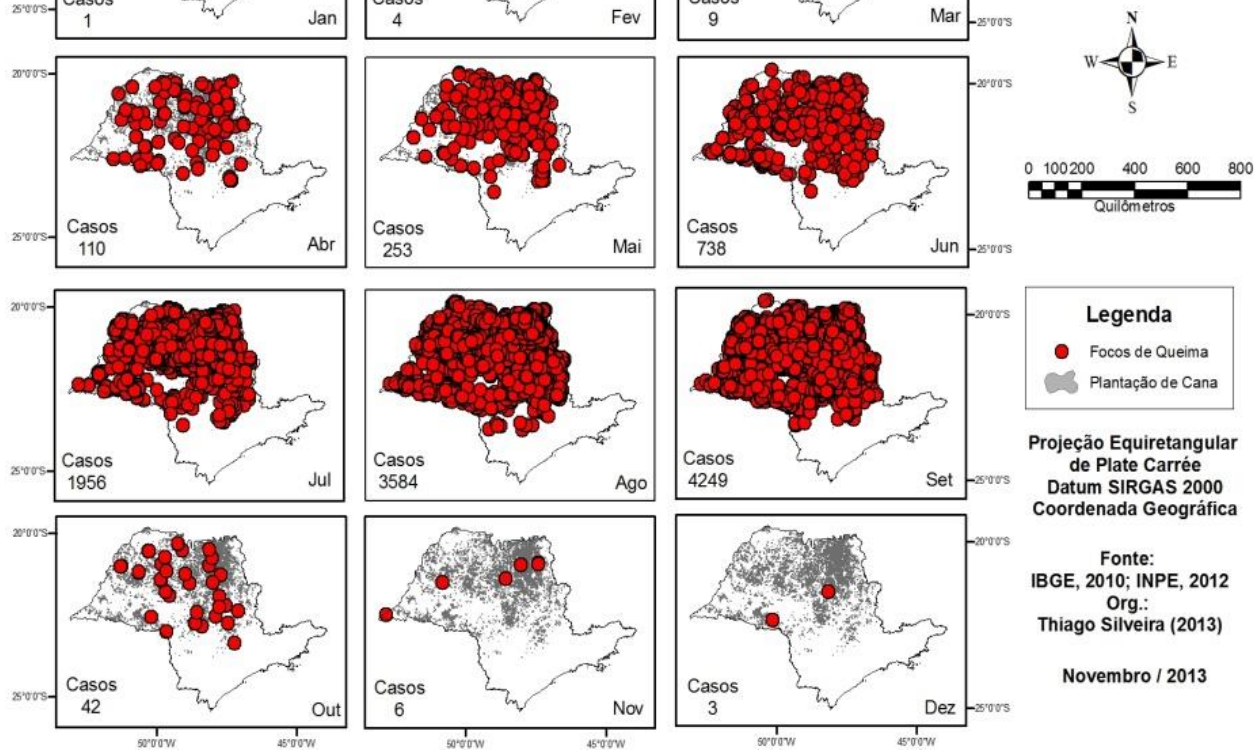

\section{CONCLUSÃO}

Os níveis de poluição de $\mathrm{CO}$ em São Paulo não são alarmantes, no entanto, há uma concentração das estações nas regiões metropolitanas. Por outro lado, o fato das medições serem baixas, há que se considerar o tempo de exposição que as pessoas ficam expostas ao poluente. A falta de estações no interior do estado não permitiu a verificação desse gás no interior, e ele faz parte das principais emissões em caso de queimadas.

Verificou-se sazonalidade na emissão de $\mathrm{CO}$ e de $\mathrm{MP}_{10}$, e em certas ocasiões ocorreu contribuição das áreas canavieiras emitindo gases e partículas na direção das regiões metropolitanas de São Paulo e Campinas. 
Canaviais contribuem com $30 \%$ do total das queimadas. É um percentual muito grande ainda, apesar de a legislação estadual prever redução desses eventos.

Apesar da modelagem CCATT-BRAMS não estar devidamente ajustada, a modelagem é importante para fazer simulações de situações onde não se pode instalar aparatos de verificação, bem como de melhorar as previsões, tanto de tempo quanto de poluição.

\section{REFERÊNCIAS}

BARROCAS, R. A queimada da cana-de-açúcar no estado de São Paulo: o exemplo de Iracemápolis. São Paulo: Universidade de São Paulo, 2001.

CETESB. Companhia Ambiental do Estado de São Paulo. Qualidade do Ar, 2010. Disponível em: <http://www.cetesb.sp.gov.br/ar/Informa?es-B?sicas/21-Poluentes>. Acesso em: set. 2011.

COMPANHIA DE TECNOLOGIA DE SANEAMENTO AMBIENTAL DE SÃO PAULO. CETESB. Redes de monitoramento, 1999. Disponível em: <http://www.cetesb.sp.gov.br/ar/lnforma?es-B?sicas/23Redes-de-Monitoramento>. Acesso em: 11 jul. 2013.

CONFEDERAÇÃO DA AGRICULTURA E PECUÁRIA DO BRASIL. Análise do PIB das cadeias produtivas de algodão, cana-de-açúcar, soja, pecuária de corte e de leite no Brasil. Sistema CNA. Brasília. 2012.

INSTITUTO NACIONAL DE PESQUISAS ESPACIAIS / CENTRO DE PREVISÃO DE TEMPO E ESTUDOS CLIMÁTICOS. Monitoramento do transporte de poluição antropogênica e de queimada na América do Sul, 1999. Disponível em:

<http://meioambiente.cptec.inpe.br/modelo_cattbrams.php?lang=pt>. Acesso em: 12 fev. 2010.

PROGRAMA CANASAT. CANASAT. Monitoramento da cana-de-açúcar, 2003. Disponível em: <http://www.dsr.inpe.br/laf/canasat/>. Acesso em: 2011.

SECRETARIA DE AGRICULTURA E ABASTECIMENTO. Levantamento censitário de unidades de produção agropecuária do estado de São Paulo. Governo de São Paulo. São Paulo. 2008.

ZANCUL, A. O efeito da queimada de cana-de-açúcar na qualidade do ar na região de Araraquara. São Carlos: Universidade de São Paulo, 1998. 